Revista Monografias Ambientais - REMOA v. 15, n.1, jan-abr. 2016, p.381-392

Revista do Centro de Ciências Naturais e Exatas - UFSM, Santa Maria

e-ISSN 22361308 - DOI:10.5902/2236130800000

\title{
PRÁTICAS DE PAISAGISMO EM ESPAÇOS DE CONVIVÊNCIA SOCIAL EM COMUNIDADES RURAIS E EM CENTRO DE EDUCAÇÃO AMBIENTAL
}

\author{
Landscaping practices in areas of social life in rural communities and environmental education \\ center
}

\begin{abstract}
Janine Farias Menegaes, Fernanda Alice Antonello Londero Backes, Karla Marque da Rocha, Karine Matuchevski Balzan
\end{abstract}

Universidade Federal de Santa Maria

Resumo

A educação socioambiental aliada às técnicas de paisagismo tem sido utilizada para melhorar a estética de ambientes proporcionando inúmeros benefícios à sociedade, contribuindo, assim, para a melhoria da qualidade de vida dos usuários destes espaços. As técnicas de ajardinamento utilizadas para a remodelação ou revitalização da paisagem são fundamentais para tornar o ambiente prazeroso e propício ao convívio social. Desse modo, o presente trabalho objetivou transmitir e desenvolver técnicas de paisagismo com a finalidade de realizar o ajardinamento de espaços de convivência social, permitindo a integração e a educação socioambiental, cultural e de preservação da vegetação que compõe estes espaços, através de oficinas temáticas intitulada Oficina de paisagismo e jardinagem. As oficinas ocorreram em dois momentos durante o dia, manhã e tarde, o período da manhã foi destinado à parte teórica sobre o tema paisagismo e jardinagem. Observou-se nas comunidades rurais que o grupo de mulheres que as mantém preocupam-se na manutenção dos espaços de convívio social e na preservação do meio ambiente e das suas culturas. Já no CEASM observou-se a preocupação dos professores em disseminar os conhecimentos relativos à ornamentação dos espaços escolares, com a finalidade de propiciar aos usuários destes espaços um ambiente prazeroso e socioeducativo.

Palavras-chave: Educação socioambiental. Paisagismo. Técnicas de jardinagem. Trabalho pedagógico.

Abstract

The environmental education coupled with landscaping techniques have been used to improve the aesthetics of environments providing numerous benefits to society, thus contributing to improving the quality of life of users of these spaces. The landscaping techniques used for remodeling or landscape revitalization are essential to make the pleasant and conducive to socializing environment. Thus, this study aimed to convey and develop landscaping techniques in order to carry out the landscaping of spaces of social interaction, allowing the integration and socio-environmental education, culture and preservation of vegetation that makes up these spaces, through thematic workshops entitled landscaping and gardening workshop. The workshops took place in two moments during the day, morning and afternoon, the morning was for the theoretical part on the topic landscaping and gardening. It was observed in the rural communities that the group of women who keeps care in the maintenance of social living spaces and the preservation of the environment and their cultures. You CEASM noted the concern of teachers to disseminate the knowledge of the ornamentation of school spaces, in order to provide users of these spaces a pleasant and childcare environment.

Keywords: Environmental education. Landscaping. Gardening techniques. Pedagogical work. 


\section{Introdução}

O paisagismo tem sido muito utilizado com o objetivo de promover conforto às pessoas que frequentam espaços de convivência social em comunidades rurais e escolares. Isto ocorre através de técnicas e práticas paisagísticas utilizando-se espécies vegetais e equipamentos mobiliários atrativos ao público usuário e, assim, embelezando o ambiente e reordenando a paisagem local. A preocupação com a reestruturação e ou remodelação do meio ambiente em espaços de convívio social comunitário e o uso correto dos recursos naturais devem ser promovidos com frequência para que as pessoas possam estar comprometidas com a preservação destes recursos socioambientais e com o bem que essas promoções trazem para as pessoas.

O maior objetivo das dimensões da educação contemporânea é o desenvolvimento de uma sociedade responsável e, a sustentabilidade é uma das perspectivas esperadas. Silva (2001) relata que as relações sociais do passado e do presente representadas por uma estrutura social estão acontecendo diante dos nossos olhos e que se manifestam através de processos e funções. Pois, ao vivermos em sociedade, como indivíduos, mantemos uma relação de independência para com o ambiente que nos envolve e uma relação de autonomia quanto às estruturas sociais nas quais nos envolvemos. Contudo, dependemos da natureza para sobreviver e da sociedade para nos desenvolver, ou seja, temos dificuldades em vivermos sozinhos, pois somos seres dependentes e associativos (SCARDUA, 2010; MENEGAES et al., 2014).

A educação socioambiental pretende desenvolver o homem de maneira que este possa adquirir valores e atitudes necessários para lidar com as situações-problemas e encontrar soluções sustentáveis (DIAS, 2003; SOUZA, 2012), além de ser um processo onde se aprende a lidar com o meio ambiente respeitando-o e a si próprio. O homem deve compreender que meio ambiente não é somente aquilo que o cerca, mas que ele próprio faz parte; é um ser que integra e interage (RAYS, 2002; SCARDUA, 2010). Segundo o Instituto Brasília Ambiental (IBRAM) entende-se por educação socioambiental os processos por meio dos quais o indivíduo e a coletividade constroem valores sociais, conhecimentos, habilidades, atitudes e competências voltadas para a conservação do meio ambiente, bem de uso comum do povo, essencial à sadia qualidade de vida e sua sustentabilidade.

Neste contexto, ao aliar a educação socioambiental às técnicas de paisagismo busca-se melhorar a estética dos ambientes e proporcionar inúmeros benefícios à sociedade, contribuindo, assim, para a melhoria da qualidade de vida dos usuários destes espaços. O ajardinamento de áreas verdes é uma percepção de melhoria no ambiente e na paisagem, que pode influenciar o comportamento individual ou de um grupo (LIRA FILHO et al., 2001).

A paisagem como consciência humana diante de um ambiente é um produto do potencial imaginativo e criativo, ou seja, é uma contemplação visual formulada através de significados e novas imagens (SEGAWA, 1996; ZANATTA et al., 2013). No meio rural, o paisagismo não está limitado ao embelezamento estético da paisagem, mas também às práticas preservacionistas, indispensáveis à manutenção dos elos essenciais ao equilíbrio do ecossistema nas áreas de sua implantação (ANGELIS, 2007). Nos espaços escolares o uso adequado dos recursos naturais são questões que devem ser inseridas no cotidiano, a fim de formar recursos humanos engajados com as causas ambientais e com as repercussões do meio sobre sua saúde. A inclusão da educação socioambiental nas escolas é necessária e fundamental para o desenvolvimento e formação das crianças e dos adolescentes como seres humanos. Esta reflexão sobre o processo de formação engloba diversos aspectos de cunho social, ambiental, econômico e político (SAHEB, 2008; CORREA, 2009).

As técnicas de paisagismo empregadas para melhorar os ambientes externos proporcionam aos usuários um espaço agradável e convidativo, favorecendo o interesse nas atividades escolares e em ambientes comunitários para a agregação dos grupos envolvidos. O paisagismo é conceituado como uma especialidade multidisciplinar de ciência e arte que tem por finalidade ordenar todo o espaço exterior em relação ao homem e demais seres vivos, a fim de torná-lo agradável ao convívio destes indivíduos (PAIVA; POST, 2008). Os princípios do paisagismo utilizados para a formação de novos espaços proporcionam aos usuários um ambiente convidativo, favorecendo o interesse nas atividades comunitárias e de convivência social. Em diversos núcleos educacionais, como por exemplo, 
comunidades rurais e escolares, em muitos casos, o que se observa é a implantação da vegetação sem o conhecimento de características importantes das espécies, como o porte, a estrutura da copa, a textura da folhagem, a cor da floração e da folhagem, a presença de plantas tóxicas, entre outros. Muitas vezes, o uso inadequado da vegetação contribui para um ambiente desagradável, desorganizado, sem funcionalidade e segurança, além de pouco inclusivo a comunidade rural, bem como a escolar.

Deste modo, o presente trabalho teve como objetivo transmitir e desenvolver técnicas de paisagismo com a finalidade de realizar o ajardinamento de espaços de convivência social, permitindo a integração e a educação socioambiental, cultural e de preservação da vegetação que compõe estes espaços, através de oficinas temáticas intitulada Oficina de paisagismo e jardinagem.

\section{Metodologia}

As oficinas temáticas intitulada Oficina de paisagismo e jardinagem foram realizadas durante o período de abril a julho de 2015, nas comunidades rurais Linha Nova, Rincão dos Pinhais e Linha dos Pomeranos no município de Agudo, RS e no centro de educação ambiental de Santa Maria, RS, por meio do projeto de extensão intitulado Práticas de paisagismo em espaços de convivência social em comunidades rurais e, como desenvolvimento do requisito parcial da disciplina MEN1212 Práticas de investigação no ensino como princípio educativo, do Curso PEG - Programa especial de formação de professores para educação profissional da UFSM.

O desenvolvido das oficinas ocorreu em conjunto com os projetos do Grupo Jardim na Escola, desenvolvidos pela Universidade Federal de Santa Maria. O Grupo Jardim na Escola é composto por professores, alunos e técnicos administrativos da UFSM, que desenvolvem projetos de pesquisa, ensino e extensão com a temática de educação socioambiental, abordando temas relacionados às técnicas de paisagismo e jardinagem. E, em parceria com a EMATER Regional Agudo na realização das oficinas nas comunidades rurais de Agudo, RS. E, com o CEASM - Centro de Educação Ambiental de Santa Maria, da Prefeitura Municipal de Santa Maria, RS, na realização da oficina neste centro. Ambos os parceiros ficaram responsáveis pela cedência do espaço físico, divulgação e agendamento das oficinas. E, por solicitar aos participantes que levassem plantas ornamentais de sua preferência e/ou que tivessem em suas casas. Essas plantas foram utilizadas para a elaboração e implantação do jardim (Tabela 1).

A oficina ocorreu em quatro dias, um dia em cada local supracitado e, a dinâmica de cada encontro aconteceu em dois momentos no dia. Primeiramente, no período da manhã, houve a exposição teórica em material audiovisual sendo abordados assuntos referentes às técnicas de paisagismo, reconhecimento e características de espécies de interesse ornamental, usos e distribuição das espécies no paisagismo, suas finalidades no jardim, uso de vasos, entre outros.

No segundo momento a oficina foi direcionada para a parte prática, com a exploração e o reconhecimento do local para a elaboração e implantação do jardim, elencando e alocando as plantas a serem utilizadas, respeitando a individualidade e pretensão de cada grupo dentro da sua localidade.

Nas comunidades rurais, ainda foi aplicado um questionário, como instrumento de coleta de dados, visando obter maiores informações a respeito dos participantes. Em virtude, da já esperada baixa escolaridade, o questionário foi elaborado com poucos e sucintos itens, como: faixa etária, sexo, tempo de residência no campo, tempo destinado aos encontros nos grupos da comunidade, frequência nos eventos na comunidade, participações em oficinas temáticas, cultivo de plantas ornamentais, entre outros. 
Tabela 1 - Plantas utilizadas em cada oficina realizada. E (exótica) e N (nativa).

\begin{tabular}{|c|c|c|c|}
\hline Oficinas & Nome comum & Nome científico & Origem \\
\hline \multirow{11}{*}{$\begin{array}{c}\text { Comunidade rural de } \\
\text { Linha Nova, } \\
\text { Agudo, RS }\end{array}$} & Barba-de-serpente & Ophiopogon jaburan & $\mathrm{E}$ \\
\hline & Cheflera & Schefflera arboricola & $\mathrm{E}$ \\
\hline & Cica & Cyca revoluta & $\mathrm{E}$ \\
\hline & Citronela & Cymbopogon winterianus Jowitt. & $\mathrm{E}$ \\
\hline & Hemerocalis & Hemerocallis sp. & $\mathrm{E}$ \\
\hline & Hortência & Hydrangea macrophylla (Thunb.) Ser. & $\mathrm{E}$ \\
\hline & Iris & Neomarica caerulea & $\mathrm{N}$ \\
\hline & Malvavisco & Malvaviscus arboreus & $\mathrm{E}$ \\
\hline & Moréia & Dietes bicolor Sweet ex Klatt & $\mathrm{E}$ \\
\hline & Periquito & Alternanthera ficoidea $L$. & $\mathrm{N}$ \\
\hline & Pingo d'ouro & Duranta erecta L. "Gold Mound" & $\mathrm{N}$ \\
\hline \multirow{16}{*}{$\begin{array}{c}\text { Comunidade rural de } \\
\text { Rincão dos Pinhais, } \\
\text { Agudo, RS }\end{array}$} & Agave & Agave sp. & $\mathrm{E}$ \\
\hline & Azaléia & Rhododendron simsii Planch. & $\mathrm{E}$ \\
\hline & Liriope & Liriope muscari & $\mathrm{E}$ \\
\hline & Cactus & Cactus sp. & $\mathrm{N} / \mathrm{E}$ \\
\hline & Cheflera & Schefflera arboricola & E \\
\hline & Clorofito & Chlorophytum comosum L. & $\mathrm{E}$ \\
\hline & Costela-de-adão & Monstera deliciosa & $\mathrm{N}$ \\
\hline & Hemerocalis & Hemerocallis sp. & $\mathrm{E}$ \\
\hline & Hibiscus & Hibiscus rosa L. & $\mathrm{E}$ \\
\hline & Hortência & Hydrangea macrophylla (Thunb.) Ser. & $\mathrm{E}$ \\
\hline & Iris & Neomarica caerulea L. & $\mathrm{N}$ \\
\hline & Jasmim & Jasminum mesnii L. & $\mathrm{E}$ \\
\hline & Malvavisco & Malvaviscus arboreus L. & $\mathrm{E}$ \\
\hline & Moréia & Dietes bicolor Sweet ex Klatt & $\mathrm{E}$ \\
\hline & Periquito & Alternanthera ficoidea $L$. & $\mathrm{N}$ \\
\hline & Barba-de-serpente & Ophiopogon jaburan & $\mathrm{E}$ \\
\hline \multirow{19}{*}{$\begin{array}{c}\text { Comunidade rural de } \\
\text { Linha dos Pomeranos, } \\
\text { Agudo, RS }\end{array}$} & Agave & Agave sp. & $\mathrm{E}$ \\
\hline & Amor-perfeito & Viola tricolor & $\mathrm{E}$ \\
\hline & Azaléia & Rhododendron simsii Planch. & $\mathrm{E}$ \\
\hline & Barba-de-serpente & Ophiopogon jaburan & E \\
\hline & Cactus & Cactus sp. & $\mathrm{N} / \mathrm{E}$ \\
\hline & Caliandra & Calliandra brevipes Benth. & $\mathrm{N}$ \\
\hline & Cheflera & Schefflera arboricola & $\mathrm{E}$ \\
\hline & Clorofito & Chlorophytum comosum L. & $\mathrm{E}$ \\
\hline & Cravina & Dianthus chinensis L. & $\mathrm{E}$ \\
\hline & Cravo-de-defunto & Tagetes erecta & $\mathrm{E}$ \\
\hline & Dracena & Dracaena sp. & $\mathrm{E}$ \\
\hline & Gazania & Alternanthera ficoidea & $\mathrm{E}$ \\
\hline & Hemerocalis & Hemerocallis sp. & $\mathrm{E}$ \\
\hline & Hibiscus & Hibiscus rosa L. & $\mathrm{E}$ \\
\hline & Iris & Neomarica caerulea L. & $\mathrm{N}$ \\
\hline & Liriope & Liriope muscari & $\mathrm{E}$ \\
\hline & Malvavisco & Malvaviscus arboreus L. & $\mathrm{E}$ \\
\hline & Moréia & Dietes bicolor Sweet ex Klatt & $\mathrm{E}$ \\
\hline & Periquito & Alternanthera ficoidea $L$. & $\mathrm{N}$ \\
\hline \multirow{7}{*}{$\begin{array}{c}\text { CEASM } \\
\text { Centro de Educação } \\
\text { Ambiental } \\
\text { de Santa Maria, RS }\end{array}$} & Clorofito & Chlorophytum comosum L. & $E$ \\
\hline & Costela-de-adão & Monstera deliciosa & $\mathrm{N}$ \\
\hline & Iris & Neomarica caerulea L. & $\mathrm{N}$ \\
\hline & Moréia & Dietes bicolor Sweet ex Klatt & $\mathrm{E}$ \\
\hline & Barba-de-serpente & Ophiopogon jaburan & $\mathrm{E}$ \\
\hline & Maranta & Maranta sp. & $\mathrm{N}$ \\
\hline & Manto-de-viúva ou Trança-de-cigana & Tradescantia sp. & $\mathrm{E}$ \\
\hline
\end{tabular}




\subsection{Oficina de paisagismo e jardinagem nas comunidades rurais}

Nas comunidades rurais de Agudo, RS, o Grupo Jardim na Escola com o projeto de extensão supracitado, ministrou a Oficina de paisagismo e jardinagem durante o dia todo. Pelo período da manhã ocorreu uma conversa inicial e integração do grupo, na sequência houve a exposição teórica dos conteúdos básicos sobre paisagismo, tais como: cores, disposição e alocação das plantas e harmonia entre as plantas e o espaço a ser revitalizado.

No período da tarde, houve a parte prática da oficina, onde o grupo de cada comunidade rural pode elaborar e implantar um minijardim no espaço de conivência escolhido pelos participantes, de acordo, com as plantas já existentes, bem como as plantas adquiridas pelo grupo. Durante a divulgação da oficina de paisagismo, via rádio, a EMATER solicitou às pessoas que iriam participar que levassem plantas de sua preferência ou que dispunham em suas residências, o que foi prontamente atendido, conforme a Tabela 1.

As Figuras 1, 2 e 3 apresentam o trabalho desenvolvido pelo Grupo Jardim na Escola e pelos participantes nas três comunidades rurais de Agudo - Linha Nova, Rincão dos Pinhais e Linha dos Pomeranos, respectivamente.

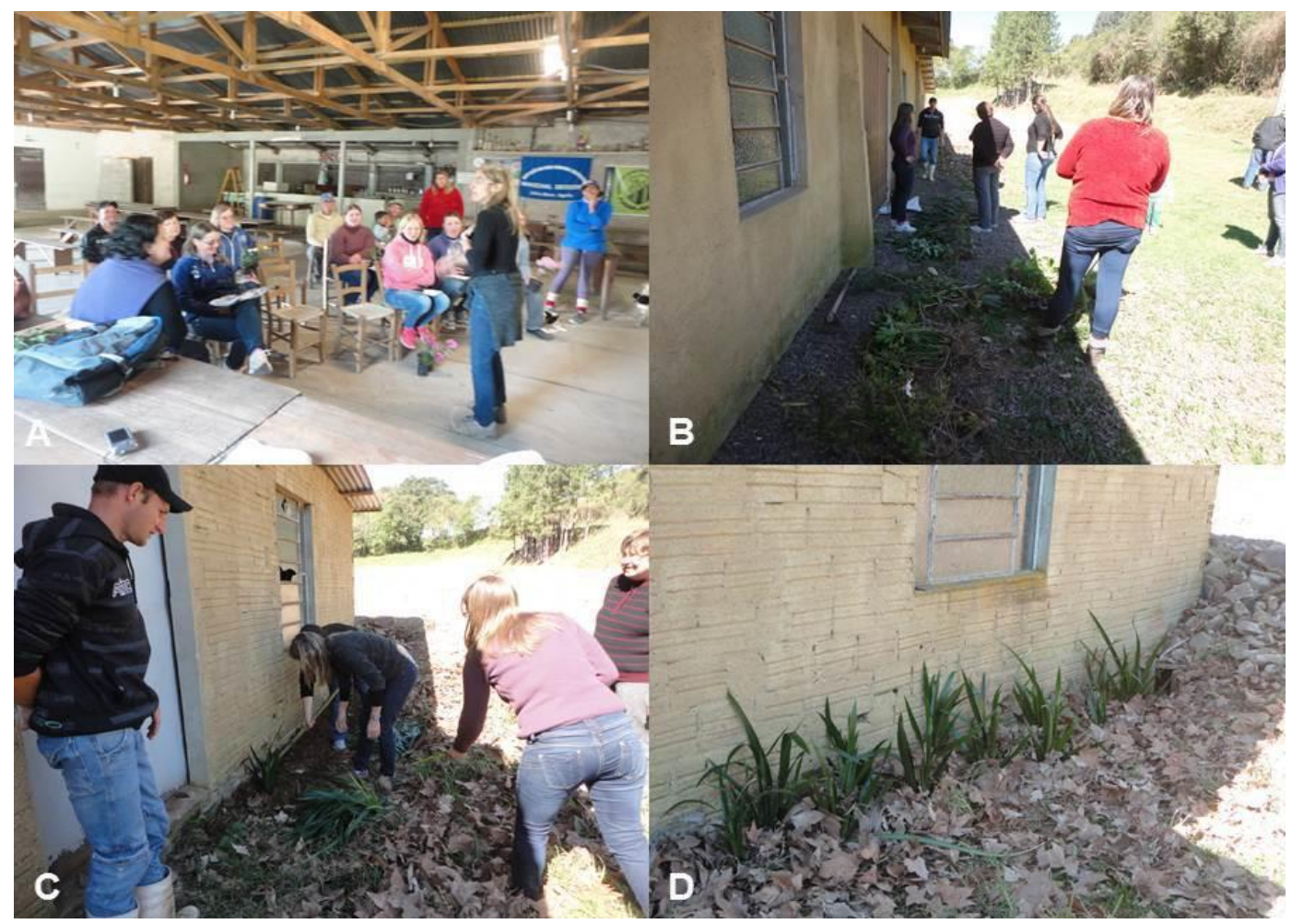

Figura 1 - Oficina de paisagismo e jardinagem na comunidade rural de Linha Nova, Agudo, RS. A - aula teórica; B - reconhecimento das espécies vegetais adquiridas pelo grupo; C - aula prática e D canteiro pronto. Fotos: Autoras. 


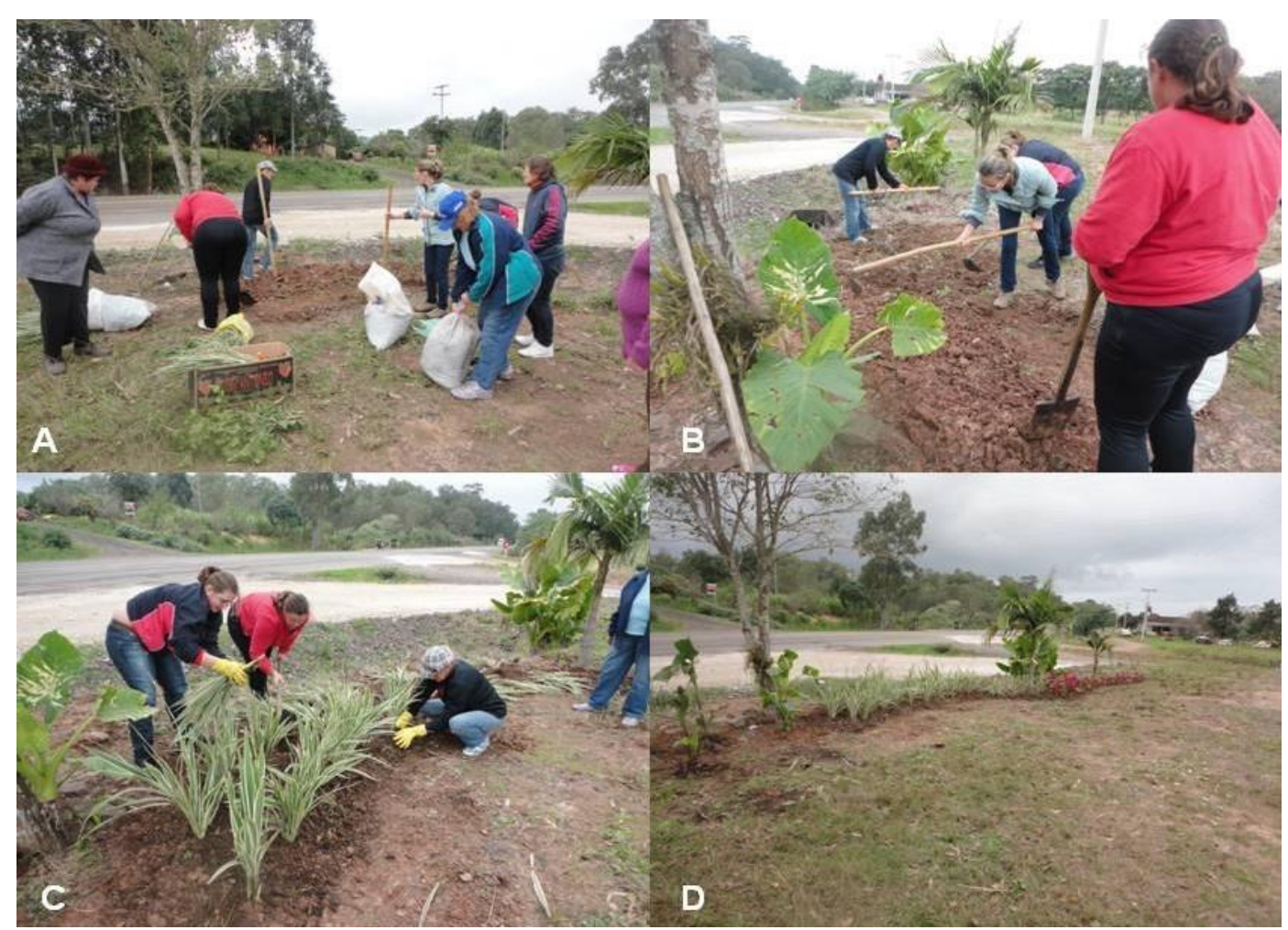

Figura 2 - Oficina de paisagismo e jardinagem na comunidade rural do Rincão do Pinhal, Agudo, RS. A e B - preparo dos canteiros; C - implantação das espécies ornamentais; D - canteiros ornamentados. Fotos: Autoras.

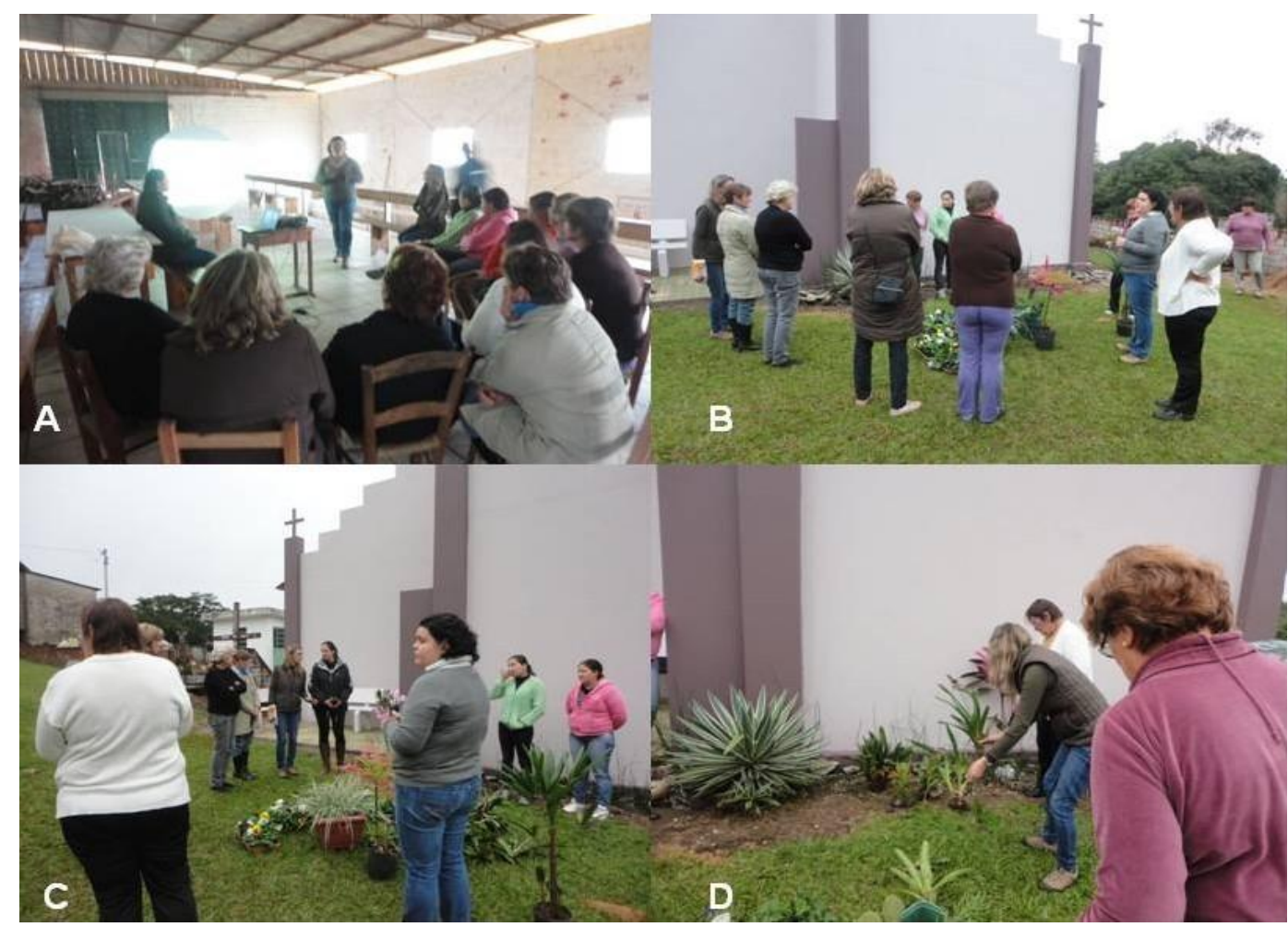

Figura 3 - Oficina de paisagismo e jardinagem na comunidade rural da Linha dos Pomeranos, Agudo, RS. A - aula teórica; B, C e D - aula prática na. Fotos: Autoras. 
O paisagismo tem como principal objetivo proporcionar o bem estar das pessoas em um determinado local, de forma a organizar e justapor plantas e elementos arquitetônicos a beneficiá-los, conforme a Figura 4. Diante desta premissa, nas comunidades onde realizamos a oficina, buscamos respeitar a cultura e a vontade de cada grupo individualmente. Observou-se, de modo geral, que os participantes da oficina preferiram a parte prática a teórica. Citando a fala da senhora Eva de 72 anos "professora eu gosto mesmo é de plantar, tenho cada flor, uma mais linda que a outra na minha casa. Às vezes, eu troco umas com as vizinhas, a gente adora flores, então a aula da manhã foi boa, mas agora vamos colocar a mão na massa, isso sim que é bom".

Notou-se que, aproximadamente $80 \%$ das participantes, na maioria mulheres, com idade acima do 50 anos e com baixa escolaridade, preferiram a aula prática, pois estão acostumadas a trabalhar na lavoura e em casa no jardim e horta. Durante a realização do questionário muitas saíram ou preferiram não responder, não por má vontade de respondê-lo, mas sim por não serem alfabetizadas.

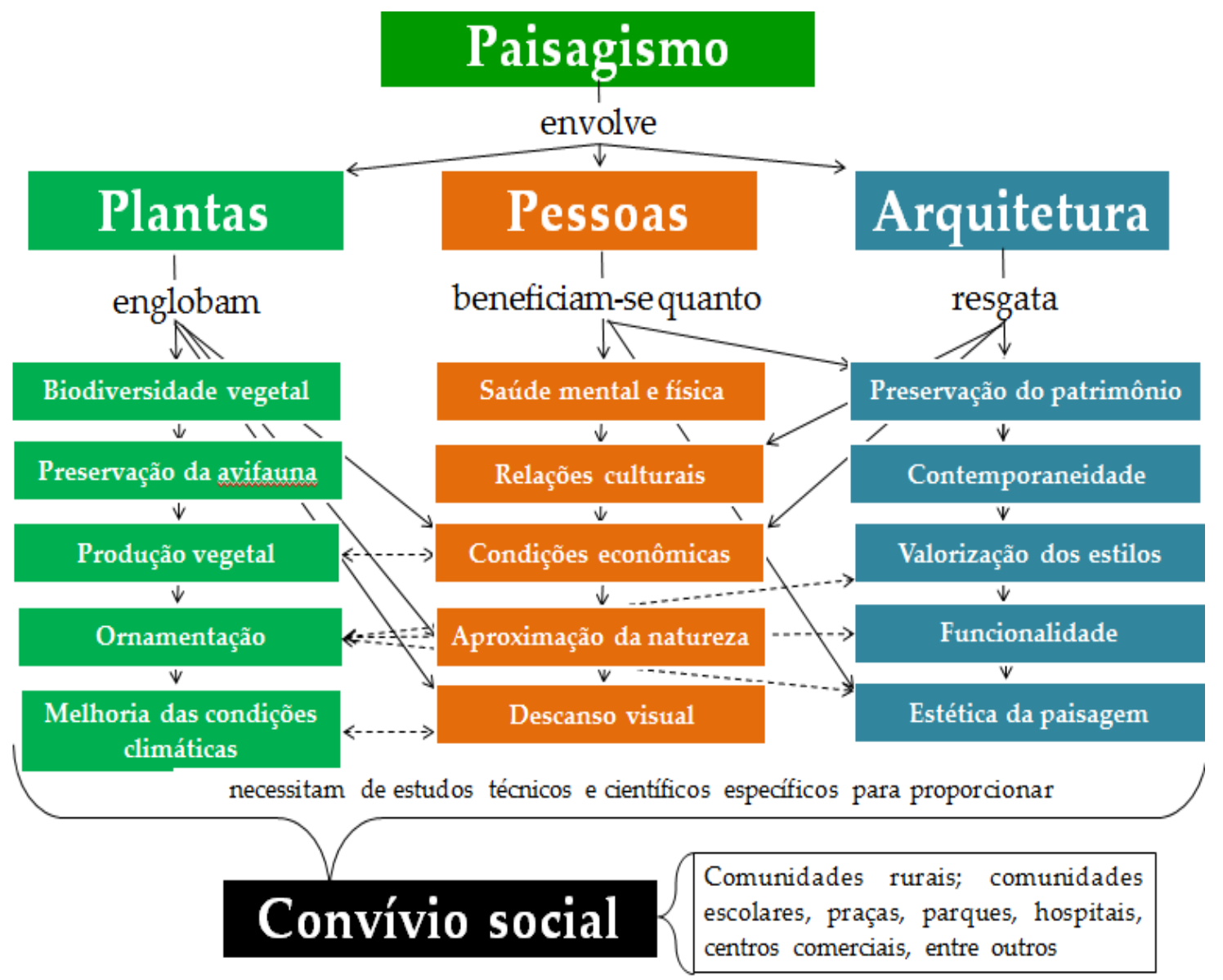

Figura 4 - Benefícios do paisagismo para o convívio social. Fonte: Autoras.

O Grupo Jardim na Escola visitou e ofereceu a Oficina de paisagismo e jardinagem a três comunidades rurais de Agudo, RS, são elas: Linha Nova, Rincão dos Pinhais e Linha dos Pomeranos. Nas três oficinas realizadas obtivemos um total de 55 pessoas, destas 50 são mulheres, dos cinco homens presentes, dois eram crianças com até 7 anos. Observa-se que nestas localidades são as mulheres as incentivadoras e mantenedoras da cultura na família e na comunidade que estão inseridas. Freitas (2011) relata que a organização de mulheres agricultoras em grupos é uma maneira de valorizá-las enquanto mulheres, observando a necessidade de se posicionarem criticamente diante da realidade em que vivem. E, que o conhecimento popular é influenciado pelo repertório cultural de cada 
comunidade, uma vez que, a população em geral, desenvolve à sua maneira diferentes formas de explorar as heterogeneidades dos ambientes adaptando-se para sua sobrevivência (PINTO et al., 2006; SOUZA, 2012).

Assim, o paisagismo como ciência oportuniza a projeção de uma nova paisagem, de acordo, com o contexto da área e da cultura local, proporcionando aos seus usuários e/ou contempladores um ambiente agradável e estético (ZANATTA et al., 2013; MENEGAES et al., 2014). O jardim passa a ser utilizado para encontros prazerosos entre amigos e familiares, além de ambiente para a leitura, meditação e relaxamento (SOARES JÚNIOR et al., 2009). Além de, também oferecer sensações como o perfume das flores, o canto dos pássaros, o frescor da brisa e até o simples ato de saborear as frutas diretamente do pé.

Na Figura 5 pode ser observada a faixa etária das participantes mulheres. Verificou-se que a maioria das mulheres participantes tem idade igual ou superior a 41 anos, também pode ser observado que as senhoras de mais idade preocupam-se em manter o convívio em comunidade, bem como, buscam preservá-las.

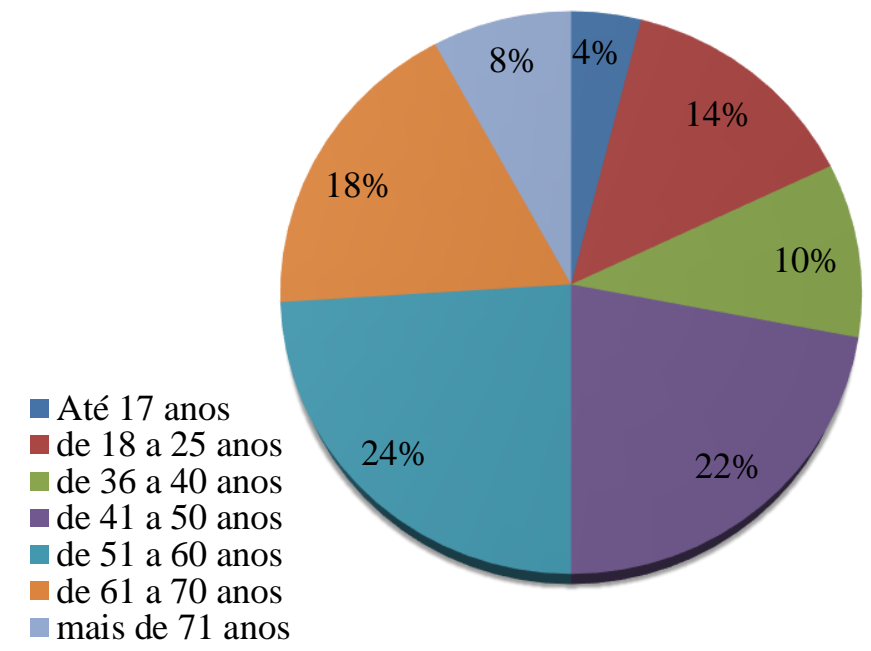

Figura 5 - Faixa etária das participantes femininas, total 50 mulheres. Fonte: Autoras.

Todas as mulheres presentes nas oficinas ministradas declararam fazer parte do grupo de mulheres da sua comunidade, observou-se que cada comunidade tem um estilo próprio de administração do seu grupo, bem como, necessidades e desejos. Em geral, os encontros ocorrem semanalmente, mas na reunião mensal é que há maior participação. Todas as comunidades rurais trabalhadas são próximas ou nas dependências de um centro religioso, composto pela igreja, pelo salão comunitário e pelo cemitério. Deste modo, em função da religiosidade fervorosa destas comunidades os encontros tendem a manter-se quinzenalmente. Contudo, os encontros destes grupos ocorrem conforme a deliberação do tema em conjunto com a EMATER Regional, que busca proporcionar melhoria de vida no campo, quer seja pelo apoio técnico como humanístico.

A realização destas oficinas foi a pedido dos grupos de mulheres das comunidades rurais supracitadas, com a intenção de melhoria no entorno do espaço de convívio social - centro religioso. Segundo relatos das líderes comunitárias elas dizem "nós mulheres queremos que nossos dias sejam mais floridos e que a nossa igreja fique linda com o paisagismo, isso nos ajuda a agradecer tudo de que recebemos do Senhor. Além de ficar mais bonito e atrair os jovens para cá, tem que ficar tudo bem ajeitadinho e bonitinho".

Verificou-se que a grande maioria das mulheres que participaram das oficinas cultivam flores e plantas ornamentais em suas casas, contudo, nunca tinham participado de uma aula ou oficina específica com este tema. Um gesto muito comum entre as agricultoras é a troca de espécies entre as mesmas. De acordo com Bellé (2000) tal fato ocorre, principalmente para aumentar a diversidade das 
plantas no jardim, especialmente com espécies diferentes e cultivadas e transmitidas de geração em geração e, para a manutenção do jardim florido em todas as épocas do ano.

Em relação ao tempo e residência no campo 100\% dos participantes relataram que residem neste meio desde que nasceram, sendo que suas propriedades foram herdadas de seus pais ou adquiridas e, que "não pretendem sair de lá". Em relação à constituição familiar, mantém-se a formação do casal mais os filhos, apenas dois casos foram relatados que os netos moram com os avós.

Salienta-se que estes grupos de mulheres advêm do meio rural, um local prazeroso e frutífero, contudo, de difícil manutenção quer seja pelo intenso trabalho quer seja pela pouca ou nenhuma valorização. Ainda preocupam-se na perpetuação dos costumes familiares, mas, principalmente, pelos religiosos, fato típico das comunidades com descendências alemãs e italianas. Em relação à participação do grupo, foi esplêndida, com participação total, a troca de experiências e conversas paralelas aos mais diversos assuntos auxiliaram na aceitação das técnicas e práticas de paisagismo e jardinagem propostas pelo Grupo Jardim na Escola.

\subsection{Oficina de paisagismo e jardinagem no centro de educação ambiental}

No centro de educação ambiental de Santa Maria, RS, o CEASM, o Grupo Jardim na Escola foi convidado a ministrar uma oficina aos professores da rede municipal de ensino, com o intuito de propagar e desenvolver jardins nas escolas municipais. Desse modo, a Oficina de paisagismo e jardinagem (Figura 6) ocorreu com a presença de 23 professores no CEASM, inicialmente, houve uma conversa inicial e as apresentações e exposições da realidade dos ambientes verdes nas escolas - o que é preocupante, pois a totalidade dos participantes relatou que em seus ambientes escolares é preciso remodelar totalmente os pátios para que os estudantes, professores e a comunidade escolar possam usufruir de maneira agradável e saudável durante os intervalos das aulas. Salientaram que o paisagismo trará inúmeros benefícios ao convívio escolar.

O centro de educação ambiental tem como objetivo formar pessoas conscientes sobre a sociedade em que estão inseridos, promovendo a cidadania e a preservação ambiental. A educação socioambiental pretende fazer com que o indivíduo e a sociedade adquiram conhecimentos e habilidades que os permitam mudar seus hábitos, posturas e atitudes, viabilizando uma convivência pacífica e racional do homem com os recursos naturais que nos envolvem e permitem a sobrevivência de todos os seres (IBRAM, 2012). Uma vez que, a cultura é um estilo de vida global de um povo, é um conjunto de orientações que visam resolver problemas recorrentes e, também são as técnicas para se ajustar tanto ao ambiente externo quanto as relações entre homens (GEERTZ, 1989; RAYS, 2002).

A dinâmica da oficina ocorreu em dois momentos, sendo a parte prática neste contexto mais explorada, pois os professores ansiavam por adquirir técnicas de paisagismo e jardinagem para colocá-las em prática nas suas escolas. Em geral, os professores presentes, já tinham tentado realizar algum projeto extraclasse sobre este tema, mas sem sucesso ao longo do tempo, às vezes por falta de incentivo da comunidade escolar de modo geral, às vezes por desânimo. Pois, devemos lembrar que plantas necessitam de cuidados frequentes e constantes, ou seja, sempre tem que ter uma pessoa responsável pelo projeto disposta diariamente na sua manutenção, além de que para a execução de um jardim é necessário a disponibilidade de mudas em quantidade e qualidade e que as verbas de escolas públicas em geral são escassas (BELLÉ, 2000; ANGELIS, 2007).

De modo geral, a preocupação e participação destes professores na oficina foram claras, a proporcionar um ambiente escolar agradável, de forma ordenada e que este ambiente sirva para atividades pedagógicas multidisciplinares. Pois, é preciso que os indivíduos, líderes ou não de comunidades, tenham força para introduzir e implantar ideias nestas comunidades, agregando aspectos ideológicos, culturais e psicológicos (LIBÂNEO, 2004; LOUREIRO et al., 2012). 


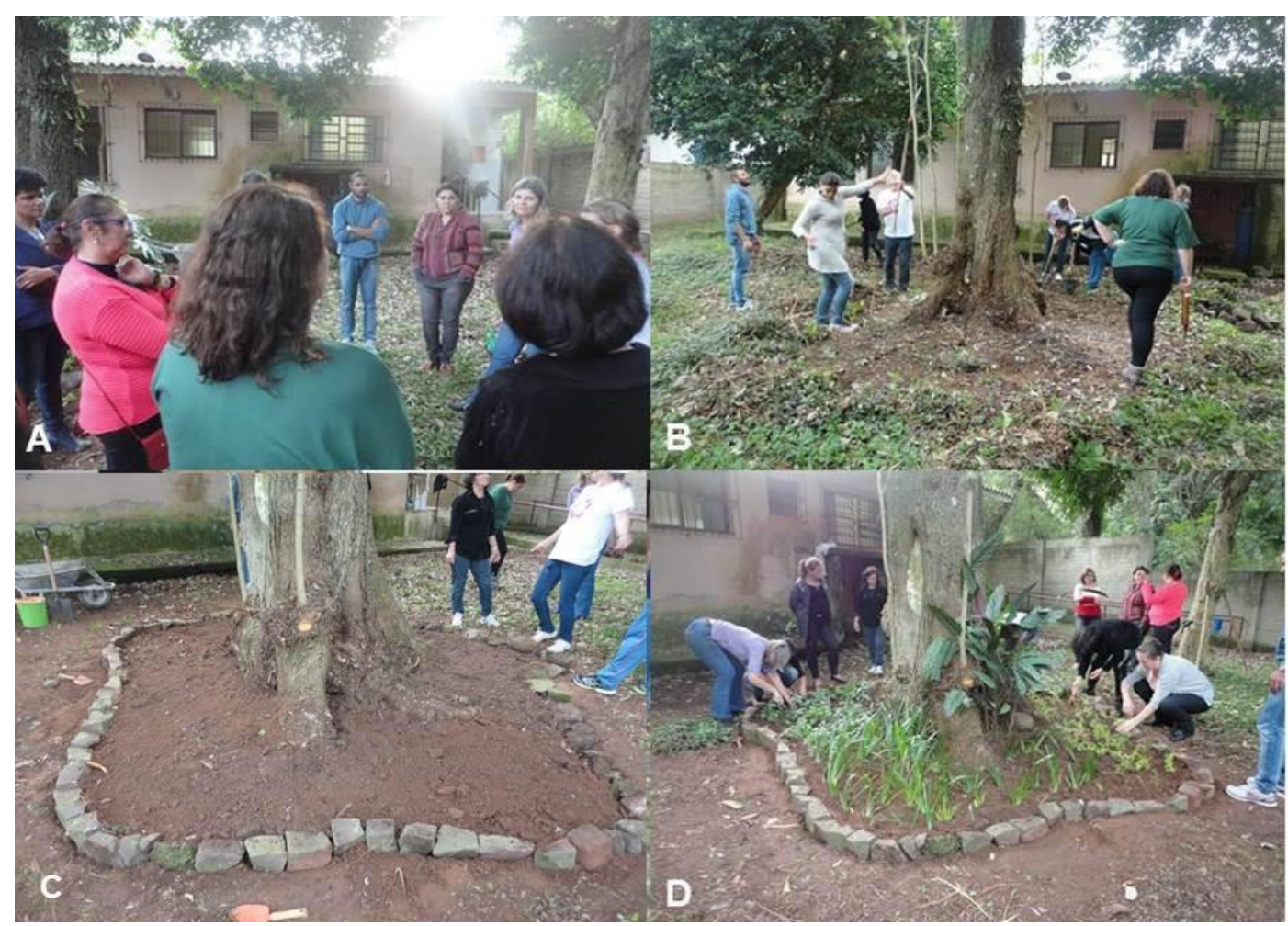

Figura 6 - Oficina de paisagismo e jardinagem no CEASM, Santa Maria, RS. A - conversa inicial para a escolha da área; B - escolha e limpeza da área; C - inicio da implantação do projeto e D finalização do projeto. Foto: Autoras.

\section{Considerações finais}

As atividades abordadas nas oficinas foram tratadas com muita seriedade pelos participantes, demonstrando interesse e participação. Nas comunidades rurais de Agudo, RS visitadas pelo Grupo Jardim na Escola, observou-se que os grupos, mesmo com suas particularidades, todos buscavam melhorar esteticamente seus espaços de convívio social. Proporcionando aos moradores rurais áreas verdes de contemplação da natureza, além da preservação do meio ambiente. E, na oficina realizada no centro de educação ambiental em Santa Maria, RS pôde-se verificar a preocupação por parte dos professores com a formação de seus alunos e também com o meio ambiente de convívio.

A preocupação com a reestruturação do meio ambiente nestes espaços de convívio social comunitário e o uso adequado dos recursos naturais são questões que devem ser inseridas no cotidiano, a fim de formar recursos humanos empenhados como as causas ambientais e com as repercussões do meio sobre sua saúde.

A receptividade do Grupo Jardim na Escola em todas as oficinas realizadas demonstra claramente que estamos todos engajados na melhoria do ambiente sendo que o convívio social é de extrema importância, principalmente, nas comunidades rurais que buscam o resgate e manutenção de sua cultura. Como no centro de formação educacional que visa difundir a educação socioambiental para a preservação do meio em que vivemos como a formação de cidadãos responsáveis e comprometidos.

\section{Referências bibliográficas}

ANGELIS, B. L. D. Material didático de Floricultura e Paisagismo, Departamento de Agronomia da Universidade de Viçosa. Viçosa. 2007. 286p. 
BELLÉ, R. A. Caderno didático de Floricultura. Curso de Agronomia, UFSM: Santa Maria. 2000. $142 \mathrm{p}$.

CORREA, R. M. (Org.) Avanços e desafios na construção de uma sociedade inclusiva. Belo Horizonte: Sociedade Inclusiva/PUC-MG, 2009. 198 p.

DIAS, G. F. Educação ambiental: princípios e práticas. 8 ed. São Paulo: Gaia, 2003. 551p.

FREITAS, L. V. M. A organização do Movimento de Mulheres Agricultoras de Santa Catarina, Igreja e Protagonismo Político no contexto da década de 1980. In: XXVI SIMPÓSIO NACIONAL DE HISTÓRIA - ANPUH. USP. São Paulo. 2011 Anais eletrônicos... Disponível em:< http://www.snh2011.anpuh.org/conteudo/view?ID_CONTEUDO=775>. Acesso em 28 maio 2015.

GEERTZ, C. A interpretação das culturas. Rio de Janeiro: LTC, 1989. 324p.

INSTITUTO BRASÍLIA AMBIENTAL. Informações/ Educação Ambiental. Brasília, 2012. Disponível em: <www.ibram.df.gov.br/informações/educacao-ambiental/o-que-e-educacao-ambienta.htm>. Acesso em: 23 maio 2015.

LIBÂNEO, J. C. A didática e a aprendizagem do pensar e do aprender: a teoria histórico-cultural da atividade e a contribuição de Vasily Davídov. Revista Brasileira de Educação, Rio de Janeiro, n. 27, p.5-24, 2004.

LIRA FILHO, J. A.; PAIVA, H. N.; GONÇALVES, W. Paisagismo - princípios básicos. Viçosa: Aprenda Fácil, 2001. 163p.

LOUREIRO, C. F. B. Trajetórias e Fundamentos da Educação Ambiental. 4. ed. São Paulo: Cortez, 2012. $168 \mathrm{p}$.

MENEGAES, J. F.; BACKES, F. A. A. L.; BALDONI, M. B.; ZAGO, A. P.; BERNARDINI, C. Ajardinamento de espaços de convivência social através de técnicas de paisagismo com mulheres agricultoras do município de Agudo, RS. II Seminário Internacional de Educação do Campo e Fórum Regional do Centro e Sul do RS: educação, memória e resistência popular na formação social da América Latina. In: Anais eletrônicos... 2014. Santa Maria.

PAIVA, P. D. O.; POST, A. P. D. O. Conceitos e caracterização do paisagismo. In: PAIVA, P.D.O. Paisagismo - conceitos e aplicações. Cap. 2. Lavras: UFLA, 2008. p.67-76.

PINTO, E. P. P.; AMOROZO, M. C. M.; FURLAN, A. Conhecimento popular sobre plantas medicinais em comunidades rurais de mata atlântica - Itacaré, BA, Brasil. Acta Botânica Brasileira, v. 20, n. 4, p.751-762, 2006.

RAYS, O. A. O conceito de aula: um dos saberes necessários à práxis pedagógica. In: RAYS, O.A. (Org.). Educação: ensaios reflexivos. Santa Maria: Pallotti, 2002. p. 84-104.

SAHEB, D. A educação socioambiental na formação em pedagogia. 2008. 113f. Dissertação (Mestrado em Educação). Universidade Federal do Paraná. Curitiba, 2008.

SCARDUA, V. M. Educação infantil, educação ambiental e educação em valores: uma proposta de desenvolvimento moral da criança em relação às questões ambientais. Revista FACEVV - Faculdade Cenecista de Vila Velha. Vila Velha. n. 4; p. 136-148; jan./jun. 2010.

SEGAWA, H. Ao amor do público: jardins no Brasil. São Paulo: Studio Nobel/FAPESP, 1996. 31p. 
SILVA, L. R. A Natureza Contraditória do Espaço Geográfico. São Paulo: Contexto, 2. ed. 2001.

SOARES JÚNIOR, D. A.; OLIVEIRA, H. S.; PEDROSA, K. M. M.; SILVA, J. G. F. Paisagismo como alternativa na educação socioambiental. IX JORNADA DE ENSINO, PESQUISA E EXTENSÃO JEPX2009. In: Anais eletrônicos ... 2009. Recife.

SOUZA, R. A. M. Educação ambiental e cidadania. In: HAMMES, V.S.; RACHWAL, M.F.G. Educação ambiental - para o desenvolvimento sustentável. Meio ambiente e a escola. Brasília: Embrapa, v.7. p.43-53, 2012.

ZANATTA, T.; ROSA, M.; SANTOS, J. V. SALAMONI, A. T. Práticas ambientais em escolas públicas de Frederico Westphalen. Revista Eletrônica em Gestão, Educação e Tecnologia Ambiental. Santa Maria. v. 14 n. 14, p. 2817- 2822, 2013. 